\section{Revista 2019 \\ Ciencia e Ingeniería Vol. 29(1) \\ Neogranadina Enero-junio 2019}

DOI: https://doi.org/10.18359/rcin.3400

\title{
Modelos de temperatura del suelo a partir de sondeos superficiales de temperatura y sensores remotos para el área geotérmica del volcán Azufral
}

\author{
Jhon Camilo Matiz-Leóna - Gilbert Fabián Rodríguez-Rodríguezb \\ - Claudia María Alfaro-Valeroc
}

\begin{abstract}
Resumen: La estimación de la distribución de calor en superficie y a profundidades someras $(20 \mathrm{~cm}$, $100 \mathrm{~cm}$ y $150 \mathrm{~cm}$ ) por medio de los sondeos superficiales de temperatura (SST) para el área geotérmica del volcán Azufral encontró anomalías entre los $6^{\circ} \mathrm{C}$ y los $20^{\circ} \mathrm{C}$. A su vez, se realizaron modelos de temperatura mediante imágenes Landsat 8 del sensor TIRS (por sus siglas en inglés), que permitieron alcanzar una aproximación de la distribución de calor en superficie con tres imágenes con fecha de toma cercanas a las fechas de levantamiento de los SST. Integrando el índice de vegetación de diferencia normalizada (NDVI, por sus siglas en inglés) (entre 0,93 y -0,563) y la topografía (alturas entre 2800 msnm y 3800 msnm) en secciones cruzadas mediante técnicas de análisis espacial, se analizaron las anomalías positivas y negativas de estas tres variables en el área geotérmica. Con la estimación del coeficiente de Pearson como método cuantitativo para el análisis de las correlaciones entre los diferentes modelos generados, se denota que existe una fuerte correlación positiva (entre 0,19 y 0,46 ) entre las temperaturas en profundidad contra las temperaturas para cada uno de los días calculados con Landsat 8 TIRS.
\end{abstract}

Palabras clave: exploración geotérmica; volcán Azufral; sondeos superficiales de temperatura; sensores remotos; NDVI; procesamiento digital de imágenes de satélite.

Fecha de recepción: 3 de abril de 2018 Fecha de aprobación: 29 de junio de 2018

Cómo citar: J. C. Matiz-León, G. F. Rodríguez-Rodríguez y C. M. Alfaro-Valero, "Modelos de temperatura del suelo a partir de sondeos superficiales de temperatura y sensores remotos para el área geotérmica del volcán Azufral", Ciencia e Ingeniería Neogranadina, vol. 29(1), pp. 19-36. https://doi. org/10.18359/rcin.3400

a Servicio Geológico Colombiano, Colombia. e-mail: jmatiz@sgc.gov.co. ORCID: https://orcid.org/0000-0002-1885-9804.

b Servicio Geológico Colombiano, Colombia. e-mail: gfrodriguez@sgc.gov.co

c Servicio Geológico Colombiano, Colombia.e-mail: calfaro@sgc.gov.co.

ORCID: https://orcid.org/0000-0001-8262-1377. 


\title{
Soil Temperature Models via Surface Temperature Surveys and Remote Sensors for the Geothermal Area of the Azufral Volcano
}

\begin{abstract}
Heat distribution estimates at the surface and shallow depths $(20 \mathrm{~cm}, 100 \mathrm{~cm}$, and $150 \mathrm{~cm})$ obtained through surface temperature surveys (STSs) in the geothermal area of the Azufral volcano found anomalies ranging between $6{ }^{\circ} \mathrm{C}$ and $20{ }^{\circ} \mathrm{C}$. Additionally, temperature models developed through Landsat 8 images from the thermal infrared sensor (TIRS) reached an approximation of the surface heat distribution based on three images captured around the dates on which the STSS were conducted. Aggregating the normalized difference vegetation index (NDVI) (between 0.93 and -0.563 ) and the topography (elevations between 2800 and $3800 \mathrm{~m}$ above sea level) in cross-sections using spatial analysis techniques, this study assessed the positive and negative anomalies exhibited by these three variables within the geothermal area. Further, using Pearson coefficient estimates as a quantitative method for analyzing the correlations between the different models generated, a strong positive correlation (between 0.19 and 0.46 ) is denoted between deep temperatures against the different surface temperatures calculated for each day using Landsat 8 TIRS.
\end{abstract}

Keywords: Geothermal Exploration; Azufral Volcano; Surface Temperature Surveys; Remote Sensing; NDVI; Digital Processing of Satellite Images.

\section{Modelos de Temperatura do Solo a Partir de Sondas Superficiais de Temperatura e Sensores Remotos para a Área Geotérmica do Vulcão Azufral}

Resumo: A estimativa da distribuição de calor na superfície e profundidades rasas $(20 \mathrm{~cm}, 100 \mathrm{~cm}$ e $150 \mathrm{~cm}$ ) obtidas por meio de sondas superficiais de temperatura (SST) na área geotérmica do vulcão Azufral encontrou anomalias entre $6^{\circ} \mathrm{C}$ e $20^{\circ} \mathrm{C}$. Adicionalmente, modelos de temperatura desenvolvidos pelas imagens Landsat 8 pelo sensor térmico infravermelho (TIRS), permitiram alcançar uma distribuição de calor aproximada na superfície baseadas em três imagens com datas próximas das quais os dados de STSs foram levantados. Agregando os índices normalizados da diferença na vegetação (NDVI, em sua sigla em inglês) (entre 0,93 e -0,563) e a topografia (elevações entre 2800 e $3800 \mathrm{~m}$ acima do nível do mar) em cortes axiais, usando técnicas de análises espaciais, foram analisadas as anomalias positivas e negativas destas três variáveis na área geotérmica. Com a estimativa do coeficiente de Pearson como método quantitativo para a análise das correlações dos diferentes modelos gerados, denota-se que há uma forte correlação positiva (entre 0,19 e 0,46) entre as temperaturas em profundidade contra as temperaturas para cada um dos dias calculadas utilizando o Landsat 8 TIRS.

Palavras chave: Exploração Geotérmica; Vulcão Azufral; Sondagem de Temperaturas Superficiais; Sensores Remotos; NDVI; Processamento Digital de Imagens de Satélite. 


\section{Introducción}

Las mediciones de temperatura en áreas de exploración geotérmica desempeñan un papel importante en la caracterización de los componentes de un sistema geotérmico (reservorio, fuente de calor, capa sello, zonas de recarga y descarga) [1]. En general, estas mediciones de temperatura se derivan de pozos de exploración y de producción, que por costos de perforación y regulación ambiental incrementan en gran medida la limitación en el uso de estas tecnologías para la adquisición de información del subsuelo [2]. Como método alternativo de adquisición de datos de temperatura, los sondeos superficiales de temperatura (SST) toman mucha relevancia en la interpretación de las anomalías de temperatura presentes en los sistemas geotérmicos. La contribución en la caracterización de anomalías de temperatura a partir de modelos extraídos por sensoramiento remoto radica en el aporte de este insumo en la etapa de exploración de recursos geotérmicos de la zona de estudio que sume en la toma de decisiones. Esta parte es circunstancial, ya que, en general, la etapa de exploración en una industria geotérmica inexistente en el territorio colombiano consume muchos recursos financieros dedicados a la identificación de los elementos del modelo conceptual para evaluar el potencial energético. Las mediciones de SST realizan una aportación en superficie de las anomalías de temperatura, lo que impacta positiva y directamente la tipificación e implementación de los usos directos y un posible potencial geotérmico en cascada para una zona como la del volcán Azufral. Técnicamente, estas mediciones de temperatura al ser someras se encuentran influenciadas por variables, como radiación solar, difusividad térmica, albedo, pendiente, relieve, profundidad en la tabla de agua, tonalidad de los materiales medidos, áreas con estaciones (verano e invierno), vegetación y clima, lo que dificulta la tipificación del calor de origen geotérmico y condiciona los valores finales de temperatura [3-5]. Sin embargo, aportan un sinnúmero de información que se consolida como la verdad adquirida en terreno frente a métodos de sensores remotos (SR) [2]. Otra de las fuentes de datos térmicos asociados a la superficie terrestre se deriva de los satélites de observación terrestre puestos en órbita. Estos sensores permiten capturar valores de radiancia en el infrarrojo cercano, incluidos en los niveles digitales del pixel, que, mediante el procesamiento digital de la imagen, pueden expresar valores en unidades de temperatura [6]. Como la toma de la imagen sugiere que la longitud de onda se vea afectada por la interferencia de la radiancia solar, la vegetación y el clima, se aplica una serie de correcciones digitales para calcular los valores de temperatura e índices de vegetación que se ajusten a la realidad geotérmica [7].

\section{Materiales y métodos}

Los modelos de temperatura superficial del área geotérmica del volcán Azufral se generaron a partir de SST con estaciones entre los $20 \mathrm{~cm}$ de profundidad y los $150 \mathrm{~cm}$ de profundidad. En la generación del modelo de temperaturas generado con imágenes de satélite, se utilizaron imágenes Landsat 8 del sensor TIRS (por sus siglas en inglés) para las térmicas (bandas 10 y 11) y del sensor OLI (por sus siglas en inglés) (bandas 4 y 5) para la generación de índices de vegetación. Para encontrar y evaluar la correlación entre los modelos generados mediante SR y SST, se corrieron pruebas estadísticas de correlación paramétricas (Pearson) considerando la normalidad de los datos [8]. Los modelos obtenidos mediante los SST se tomaron como verdad terreno en la validación de los modelos calculados a partir de imágenes de sensores remotos. Como parte final de la metodología, se incluyó el cálculo del índice de vegetación diferencial normalizado (NDVI, por sus siglas en inglés), generado con las bandas del rojo visible y el infrarrojo cercano (NIR, por sus siglas en inglés) [9] y que permite identificar espacialmente la densidad y el tipo de vegetación viva, con el objetivo de corroborar las variaciones espaciales de la temperatura de superficie con la presencia de vegetación [10].

\section{Zona de estudio}

La zona de estudio de los SST dentro del área geotérmica del volcán Azufral se encuentra localizada entre los $0^{\circ} 54^{\prime} \mathrm{N}$ y los $1^{\circ} 10^{\prime} \mathrm{N}$ de latitud, y los 
$77^{\circ} 33^{\circ} \mathrm{W}$ y los $77^{\circ} 47^{\prime} \mathrm{W}$ de longitud, que abarca las cabeceras municipales de los municipios de Túquerres, Sapuyes y Guachucal, que bordean la parte alta del volcán Azufral, donde se localiza la laguna Verde. Esta zona se encuentra enmarcada en la parte central del departamento de Nariño (macizo nariñense), perteneciente al nudo de los Pastos, en la frontera colombo-ecuatoriana, donde el área geotérmica se encuentra en una zona con altitudes entre 2500 y $3150 \mathrm{msnm}$ [11].

\section{Materiales}

\section{Sondeos superficiales de temperatura}

La red de muestreo se elaboró con 329 estaciones con medidas a $150 \mathrm{~cm}$ de profundidad, 262 estaciones con mediciones a $100 \mathrm{~cm}$ de profundidad y 349 estaciones a $20 \mathrm{~cm}$ de profundidad [11]. Las perforaciones se realizaron a las profundidades descritas en un mismo punto de muestro, con un tiempo de medición aproximado de 2 min para garantizar la estabilidad térmica del subsuelo en cada medición. La toma de datos se llevó a cabo en tres intervalos de tiempo: entre el 31 de enero y el 6 de febrero de 2015, entre el 4 de agosto y el 21 de agosto de 2015, entre el 11 de septiembrey el 30 de septiembre de 2015 y entre el 13 de septiembre y el 24 de septiembre de 2016.

\section{Imágenes Landsat 8 sensores OLI y TIRS}

Las imágenes procesadas se descargaron bajo los siguientes criterios: fechas de toma cercanas a las fechas de perforación de los SST y nubosidad menor o igual al 15\% en cada escena. Las imágenes descargas tienen por fecha de toma el 15 de septiembre de 2015 y el 20 de noviembre de 2016. La inclusión de la imagen de noviembre de 2016 se debe a la poca disponibilidad de imágenes libres de nubosidad en el área de trabajo para el segundo semestre del año en mención. A su vez, y debido a que el porcentaje de nubosidad para las fechas de toma de las imágenes Landsat fuese coincidente con las fechas de toma de datos en campo para los SST, se incluyó una imagen con fecha de toma del 23 de enero de 2017, con un porcentaje de nubosidad menor del 10\%. De estas imágenes se utilizaron las bandas térmicas, números 10 y 11 del sensor TIRS, con longitudes de onda de 10,6011,19 y $11,50-12,51 \mu \mathrm{m}$, respectivamente, con resolución espacial de $100 \mathrm{~m}$, remuestrada a $30 \mathrm{~m}$, y las bandas rojo e infrarrojo cercano del sensor OLI (longitud de onda entre $0,64 \mu \mathrm{m}$ y $0,88 \mu \mathrm{m}$ con resolución espacial de 30m) [12].

\section{Modelo digital de elevación SRTM de $30 \mathrm{~m}$}

Las alturas de la zona de estudio se trabajaron según el modelo digital de elevación (MDE, por sus siglas en inglés) de la National Aeronautics and Space Administration (NASA) y la National Geospatial-Intelligence Agency (NGA), conocido como el Shuttle Radar Topography Mission (SRTM), con una precisión global de $1 \mathrm{~s}$ de arco o su equivalente en sistemas de referencia proyectados a $30 \mathrm{~m}$ [13].

\section{Métodos}

\section{Sondeos superficiales de temperatura}

Temperaturas superficiales. La toma de datos en campo consistió en la perforación de los sondeos a las profundidades de $20 \mathrm{~cm}, 100 \mathrm{~cm}$ y $150 \mathrm{~cm}$, con una distancia de separación entre sondeos de $1 \mathrm{~km}$ de espaciamiento [11]. Para la representación de las temperaturas, se generó un análisis estadístico para cada uno de los conjuntos de datos a distintas profundidades registradas, compuesto de diagramas cuantil-cuantil (Q-Q), semivariogramas y revisión de la tendencia global de los datos [11]. El cálculo de la temperatura superficial se basó en la ecuación (1). Donde: $T_{s}^{o}$ corresponde a la temperatura media anual del aire en ${ }^{\circ} \mathrm{C}$ y $h$ a la altitud en $\mathrm{m}$ [14].

$T_{s}^{o}=28,1-0,00553{ }^{\star} h$

Normalización de las temperaturas con referencia a la $T_{s}{ }^{o}$. Considerando que los sondeos de temperatura fueron medidos en épocas distintas y que la variación diaria de los rayos solares, según el momento del día, influye en los valores de temperatura medidos en superficie del suelo y los medidos en profundidad, se hizo necesario normalizar los datos en función de la altura. Para eliminar el 
efecto del sol en cada uno de los valores registrados [11], se calculan las diferencias de las temperaturas halladas en profundidad y la $T_{s}^{o}$ (ecuación 2). Donde: $T_{\text {norm }}^{o}$ es la temperatura normalizada y $T_{\text {prof }}^{o}$ la temperatura medida en profundidad.

$T_{\text {norm }}^{o}=T_{\text {prof }}^{o}-T_{s}^{o}$

Geoestadística. Se aplicó el método de Kriging Simple, utilizando el modelo teórico del variograma gaussiano, un lag o rezago (h) de hasta 1000 $\mathrm{m}$ de distancia y un parámetro de vecindad correspondiente al número de vecinos involucrados en la interpolación espacial (15 sondeos) [11].

\section{Procesamiento digital de imágenes de satélite}

Cálculo de temperaturas superficiales. El cálculo de las temperaturas a partir de las imágenes Landsat 8 consiste en la transformación de los niveles digitales (ND) a valores de radiancia por medio de la ecuación (3) [12]. En el metadato de cada imagen, se encuentran los respectivos coeficientes de reescalamiento radiométrico: radiancia multibanda $_{x}$ corresponde al factor de ajuste multiplicativo de la radiancia en cada banda, bandatérmica ${ }_{x}$ a la banda térmica del sensor TIRS por utilizar y radiancia add_ banda $_{x}$ al factor de ajuste aditivo de la radiancia en cada banda utilizada [12]. Este procedimiento se puede aplicar en las ecuaciones (3) y (4) para las bandas 10 y 11 del sensor TIRS [15].

radiancia multibanda $_{x}{ }^{*}$ bandatermica $_{x}+$ radianciaadd_banda $a_{x}$

Posteriormente, la radiancia se transforma en valores de temperatura de brillo aparente $T_{\text {Kelvin }}$ (ecuación 4). Donde: K1 y K2 corresponden a las constantes de conversión térmica para cada banda de la imagen y $L \lambda$ es la reflectancia en el parte superior de la atmósfera-TOP (Top of Atmosphere) [12]. La temperatura calculada es representada en grados Kelvin, por lo que se transforma a grados Celsius (ecuación 5) [12]. Este procedimiento se puede aplicar para las bandas 10 y 11 del sensor TIRS [15].

$$
T_{\text {Kelvin }}=\frac{K 2}{\ln \left(\frac{K 1}{L \lambda}+1\right)}
$$

$$
T_{\text {Celsius }}=T_{\text {Kelvin }}-273,15
$$

Normalización de las temperaturas con referencia a la $T s^{\circ}$. Para comparar las diferencias de temperaturas en profundidad eliminando el efecto del sol, se aplicó la normalización realizada a valores de temperatura calculados a partir de las bandas térmicas de Landsat, tomando como base la temperatura superficial calculada con las imágenes TIRS - $T_{\text {Sup_Landsat. }}^{\text {o }}$

Cálculo del índice de vegetación. En la estimación del índice de vegetación diferencial normalizado (NDVI, por sus siglas en inglés), se transformaron los ND de reflectancia del rojo visible y del NIR en índices para cada pixel mediante la ecuación (6) [16].

$$
N D V I=\frac{N I R-\text { Rojo }}{N I R+\text { Rojo }}
$$

\section{Correlación entre variables}

Coeficiente de Pearson. Un coeficiente de correlación mide el grado de relación existente entre dos variables aleatorias [17]. El coeficiente de Pearson (ecuación 7) mide el grado de asociación entre dos variables aleatorias cuantitativas con distribución normal bivariada conjunta [8]. Donde: $\rho_{X . Y}$ es el coeficiente de correlación de Pearson, $\sigma_{X Y}$ la covarianza de las variables $X Y, \sigma_{X}$ la desviación estándar de la variable $X$ y $\sigma_{Y}$ la desviación estándar de la variable $Y[17]$.

$\rho_{X . Y}=\frac{\sigma_{X Y}}{\sigma_{X} \sigma_{Y}}$, donde $-1 \leq \rho_{X, Y} \leq 1$

Para el análisis correlacional entre la misma variable de temperatura proveniente de dos fuentes de información distinta (verdad terreno $=$ SST e hipótesis $=\mathrm{SR}$ ), la correlación se realizó pixel a pixel, al transformar cada imagen (interpolada y procesada) como un arreglo matricial y tratada en el ambiente estadístico $\mathrm{R}$ Project, bajo el proyecto GNU open source. 


\section{Resultados y discusión}

\section{Sondeos superficiales de temperatura}

Según el método Kriging Simple, se generaron los mapas interpolados considerando los criterios de la media y el error medio cuadrático estimados para cada superficie interpolada, que estuvieron cercanos a 0 y con una proximidad de 1 , respectivamente. En la figura 1, se denotan las anomalías de temperatura medidas en superficie (figura $1 \mathrm{~b}$ ) a los $20 \mathrm{~cm}$ (figura 1c), a los $100 \mathrm{~cm}$ (figura 1d) y a los $150 \mathrm{~cm}$ (figura 1e) de profundidad. También se observan las anomalías de temperatura calculadas en función de la altura a partir de la ecuación (1) para cada SST registrado (figura 1a). Se incluyeron las temperaturas normalizadas para cada una de las profundidades (figuras 1f, 1g, 1h), lo que permite disminuir el efecto de la radiancia del sol conocido como albedo y obtener anomalías de temperaturas corregidas. En general, las anomalías presentes en el área de estudio son las mismas para la mayoría de grillas. Se evidencia un alto de temperatura en la parte noroccidental, ubicado al oeste del volcán Azufral. Donde se encuentra ubicado el volcán, la coincidencia central es una anomalía negativa tanto para las grillas superficiales (entre los $6^{\circ} \mathrm{C}$ y $8^{\circ} \mathrm{C}$ ) como para las grillas en profundidad (entre los $8^{\circ} \mathrm{C}$ y $10^{\circ} \mathrm{C}$ ). Otra zona que denota una anomalía muy marcada se ubica sobre la cuenca de tracción de la falla Guachucal, que, siendo una anomalía positiva, alcanza temperaturas entre los $14^{\circ} \mathrm{C}$ y $16^{\circ} \mathrm{C}$ en superficie, con un aumento hasta los $17^{\circ} \mathrm{C}$ a una profundidad de $150 \mathrm{~cm}$. Esta anomalía al profundizarse extiende los valores altos de temperatura por toda la falla Guachucal, que tiene un sentido suroeste-noreste, alcanza temperaturas hasta los $18,5^{\circ} \mathrm{C}$ (figura $1 \mathrm{~h}$ ) y forma un corredor de alta temperatura por todo el trazo de la falla. Corrigiendo el efecto del albedo mediante la normalización de los datos medidos en profundidad, en función de la cota altitudinal, las figuras 1f, $1 \mathrm{~g}$ y 1 h denotan una caracterización de las anomalías formadas en el volcán Azufral y el corredor anómalo por la falla Guachucal como anomalías negativa y positiva, respectivamente. También se resaltan dos anomalías localizadas en los sectores noreste y suroeste del área de estudio como anomalías positivas, pero posiblemente asociadas a efectos de borde por estar al límite de la extensión de los SST con datos medidos. En la representación de los mapas de temperatura superficial medida y calculada, la escala de colores se diferenció entre tonos azules (temperaturas bajas), tonos verdosos (temperaturas medias) y tonos rojos (temperaturas altas).

\section{Landsat 8 TIRS: temperatura}

Las temperaturas calculadas a partir de las imágenes Landsat para los días seleccionados muestran diferencias por ser capturadas en distintos momentos del tiempo. En la figura 2a, se observa una anomalía negativa que oscila entre los $1^{\circ} \mathrm{C}$ y los $4^{\circ} \mathrm{C}$ en la parte central del área de estudio. Se denota una concentración de temperaturas más altas (entre los $14^{\circ} \mathrm{C}$ y los $23^{\circ} \mathrm{C}$ ) que cubre la cabecera municipal del municipio de Túquerres y parte del trazo noreste de la falla Guachucal. Para los días 20/11/2016 (figura 2e) y 23/1/2017 (figura 2i), existe una similitud en el rango de temperaturas presente entre las fallas Muellamues y la falla Guachucal (entre los $19^{\circ} \mathrm{C}$ y $22^{\circ} \mathrm{C}$ ). La zona del volcán Azufral registra rangos entre los $6^{\circ} \mathrm{C}$ y los $18^{\circ} \mathrm{C}$, lo que representa una anomalía negativa a $3900 \mathrm{msnm}$ aproximadamente. Normalizando las temperaturas en función de la profundidad de cada SST, se observa que, para las temperaturas del 15/9/215 (figuras 2b, 2c, 2d) a los $150 \mathrm{~cm}$ de profundidad, se muestran anomalías positivas hacia la parte sureste del área de estudio en forma semicircular. En cuanto a las temperaturas normalizadas para el día 20/11/2016 (figuras 2f, 2g, 2h), a la profundidad de $100 \mathrm{~cm}$ se observa una anomalía positiva de temperatura localizada en la zona del volcán Azufral. A los $150 \mathrm{~cm}$, se sigue observando la anomalía positiva (de forma semicircular) cercana a la cabecera municipal de Túquerres y a una parte del trazo de la falla Guachucal. Para las temperaturas del día 23/1/2017 (figuras 2j, 2k, 2l), se denota una similitud en las anomalías positivas ubicadas en inmediaciones del volcán Azufral. En la parte de la cuenca de tracción asociada a la falla Guachucal, cercana a la cabecera municipal 


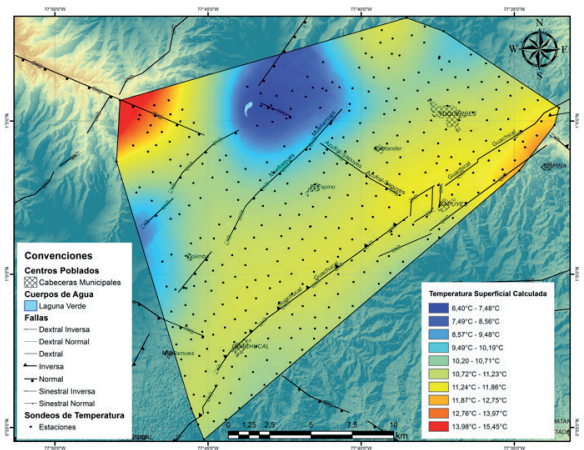

a) Temperatura superficial calculada

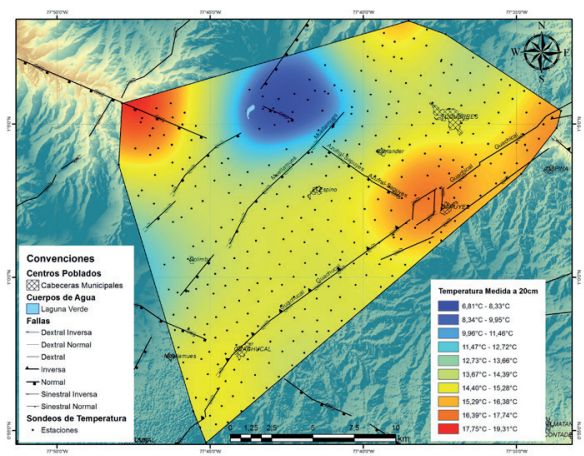

c) Temperatura medida a $20 \mathrm{~cm}$ de profundidad

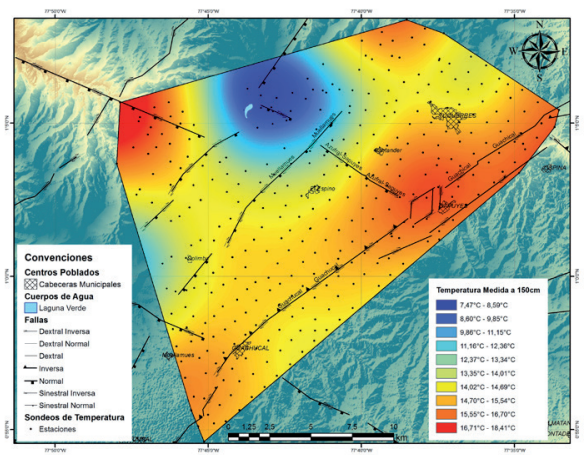

e) Temperatura medida a $150 \mathrm{~cm}$ de profundidad

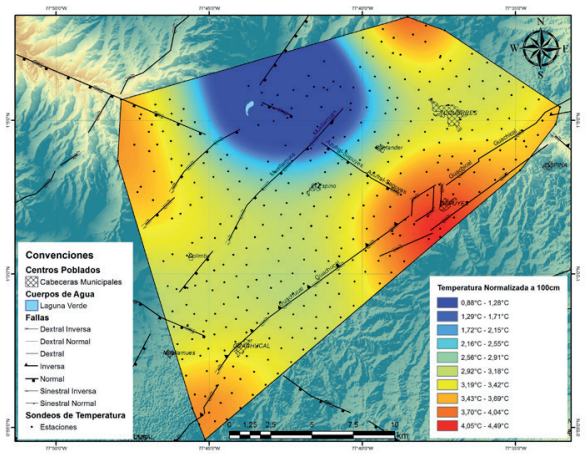

g) Temperatura normalizada a $100 \mathrm{~cm}$ de profundidad

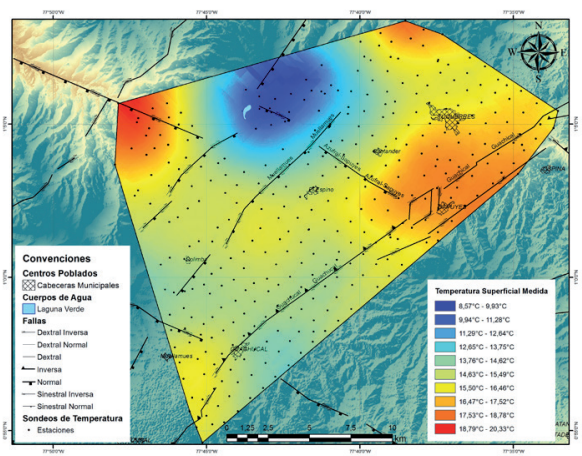

b) Temperatura superficial medida a $0 \mathrm{~cm}$

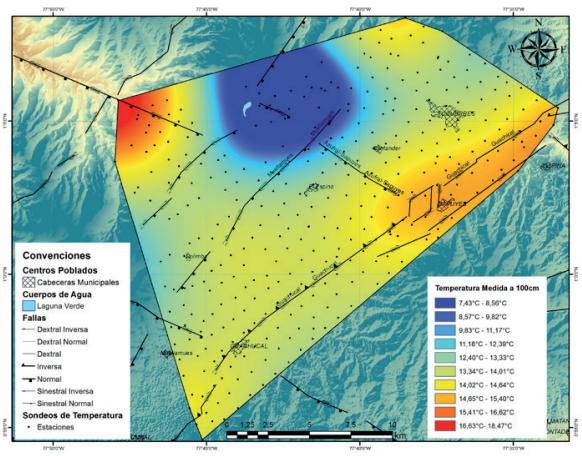

d) Temperatura medida a $100 \mathrm{~cm}$ de profundidad

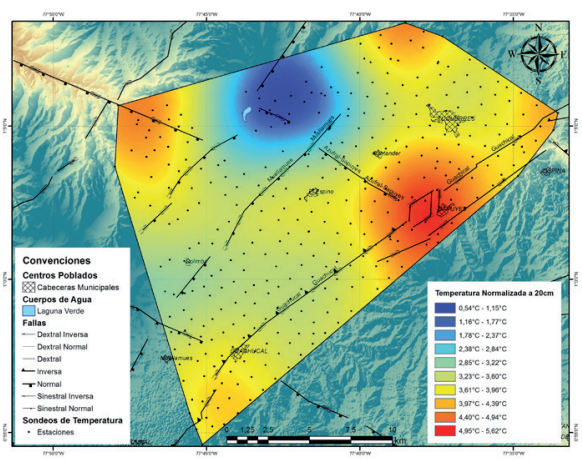

f) Temperatura normalizada a $20 \mathrm{~cm}$ de profundidad

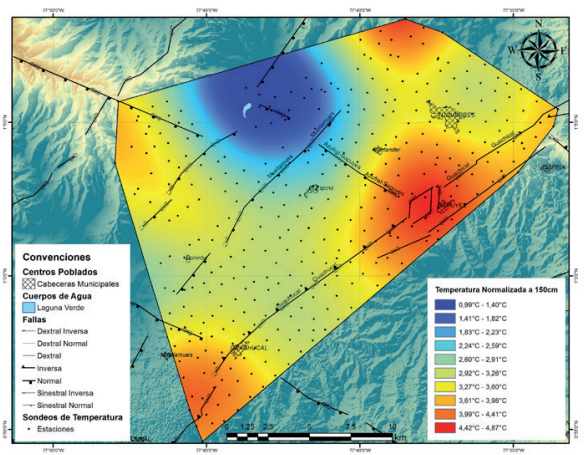

h) Temperatura normalizada a $150 \mathrm{~cm}$ de profundidad

Figura 1. Temperaturas a partir de los SST. Fuente: Para figuras $1 \mathrm{a}, 1 \mathrm{c}, 1 \mathrm{~d}, 1 \mathrm{e}, 1 \mathrm{~g}$ y $1 \mathrm{~h}$ [11] y para figuras $1 \mathrm{~b}$ y $1 \mathrm{f}$ elaboración propia. 
de Sapuyes, se aprecia una anomalía negativa circundante al trazo noreste de la falla Guachucal. Entre los trazos suroeste de las fallas Mellamues y Guachucal, se observa un corredor de anomalías positivas al suroeste del municipio de El Espino. Para la generación de los mapas de temperatura a

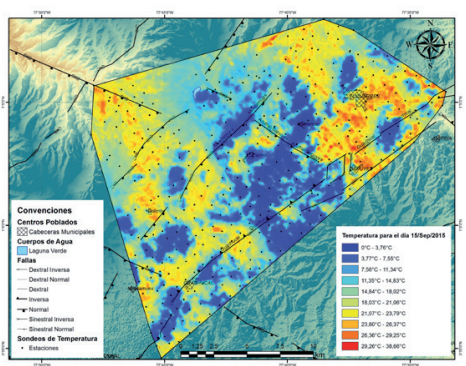

a) Temperatura para el día 15/9/2015

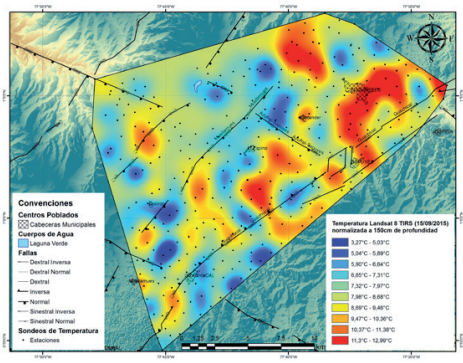

d) Temperatura para el día 15/9/2015 normalizada a $150 \mathrm{~cm}$

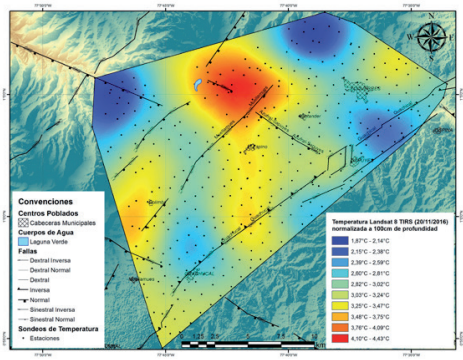

g) Temperatura para el día 20/11/2016 normalizada a $100 \mathrm{~cm}$

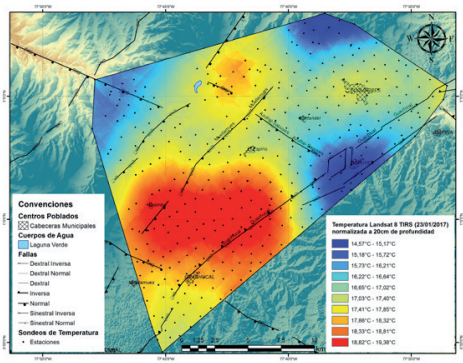

j) Temperatura para el día 23/1/2017 normalizada a $20 \mathrm{~cm}$

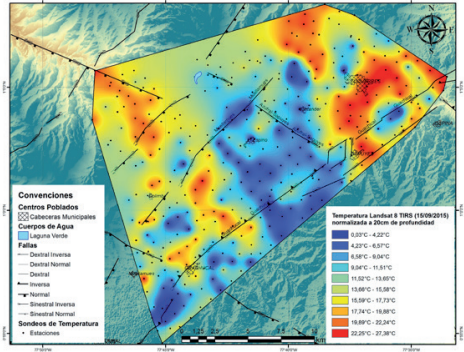

b) Temperatura para el día 15/9/2015 normalizada a $20 \mathrm{~cm}$

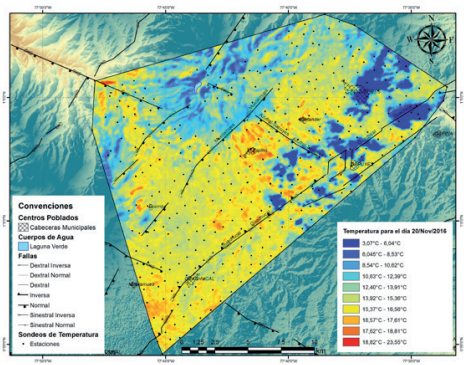

e) Temperatura para el día 20/11/2016

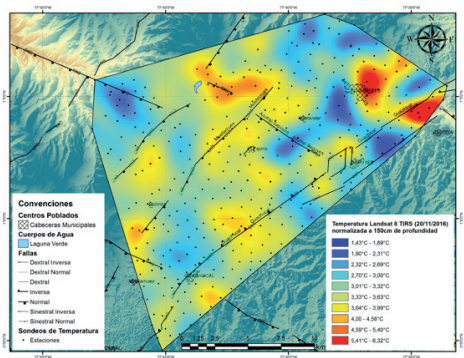

h) Temperatura para el día 20/11/2016 normalizada a $150 \mathrm{~cm}$

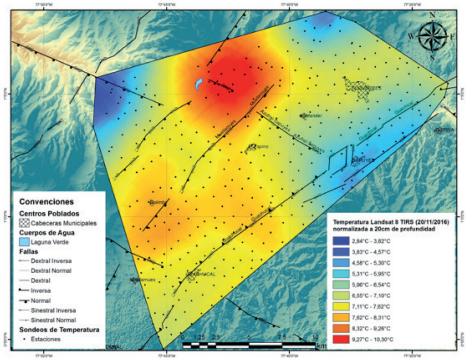

k) Temperatura para el día 23/1/2017 normalizada a $100 \mathrm{~cm}$

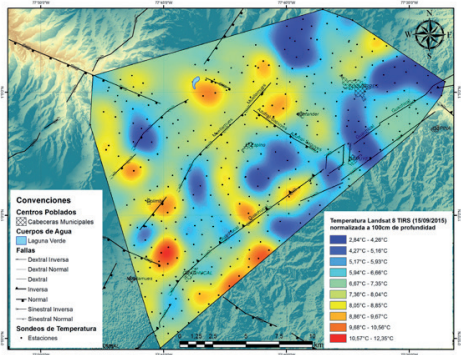

c) Temperatura para el día 15/9/2015 normalizada a $100 \mathrm{~cm}$

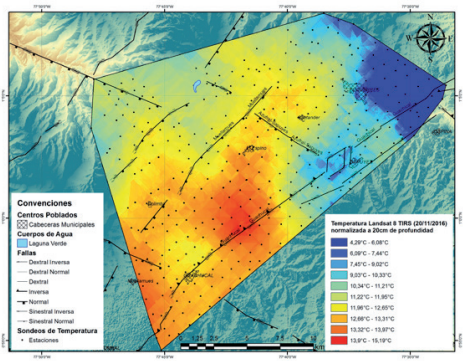

f) Temperatura para el día 20/11/2016 normalizada a $20 \mathrm{~cm}$

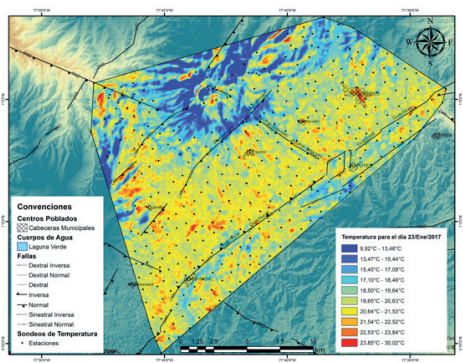

i) Temperatura para el día 23/1/2017

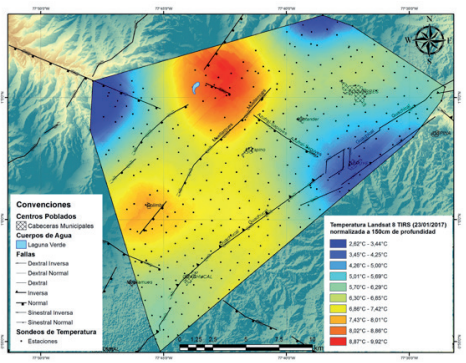

I) Temperatura para el día 23/1/2017 normalizada a $150 \mathrm{~cm}$

Figura 2. Temperaturas a partir de Landsat 8 TIRS. Fuente: Elaboración propia. 
partir de Landsat 8, la escala de colores se representó entre matices azules (temperaturas bajas), matices verdosos (temperaturas medias) y matices rojos (temperaturas altas).

\section{Correlación estadística}

Las correlaciones estimadas a partir del coeficiente de Pearson (tabla 1) son positivas, estas explican que las temperaturas calculadas y medidas aumentan de forma directa y proporcional frente a las temperaturas calculadas con las imágenes Landsat 8 TIRS. Las correlaciones más altas se encontraron para la temperatura por SR para el día 23/1/2017 en comparación con la temperatura calculada en función de la altura $(0,4388)$ y la temperatura medida en superficie $(0,3627)$. Las correlaciones halladas para los días 15/9/2015 se expresan como correlaciones positivas $(0,2104$ y 0,2746$)$, así como las correlaciones para el día 20/11/2016, pero teniendo una de las más cercanas a cero con una correlación de 0,0547 con la temperatura medida en superficie, lo que denota una correlación lineal casi inexistente.

Tomando como base las temperaturas calculadas para cada una de las imágenes Landsat 8 TIRS y las temperaturas normalizadas en función de cada una de las profundidades perforadas, se encontraron correlaciones positivas, negativas y sin existencia de correlación lineal directa entre las temperaturas normalizadas (tabla 2). El coeficiente de Pearson arrojó que, para la temperatura medida a $20 \mathrm{~cm}$, y contrastada frente a las temperaturas estimadas a partir de Landsat 8 TIRS, se tienen correlaciones positivas en todos los años (entre 0,1588 y 0,4051). Para las temperaturas normalizadas a $20 \mathrm{~cm}$ de profundidad, las correlaciones tuvieron un comportamiento negativo para las imágenes de 2016 y 2017. En cuanto a las temperaturas encontradas a $100 \mathrm{~cm}$ de profundidad, los coeficientes de correlación se calcularon positivamente (entre 0,1947 y 0,4480), a su vez, para las temperaturas normalizadas a $100 \mathrm{~cm}$ de profundidad, existe una correlación negativa con las imágenes de 2016 y 2017.

Por último, los coeficientes hallados para las temperaturas a profundidades de $150 \mathrm{~cm}$ corresponden a correlaciones positivas (entre 0,1954 y 0,4677). Para las temperaturas normalizadas, los coeficientes alcanzados para 2015 y 2016 son de correlación positiva $(0,2994$ y 0,3727 , respectivamente), pero la correlación es negativa con un coeficiente muy alto en relación con las temperaturas de 2017.

\section{Landsat 8 OLI: NDVI}

Los NDVI fueron calculados para cada una de las escenas utilizadas en la investigación (días 15/9/2015, 20/11/2016, 23/1/2017). Las tonalidades rojas (valores cercanos a 1) representan una densa vegetación con mayor verdor, los tonos verdes (valores cercanos a -1) denotan otro tipo de vegetación o cobertura (nubes y nieve) y los tonos amarillos (cercanos a 0) muestran suelo desnudo o vegetación de baja densidad [18]. Los índices de vegetación para cada una de las escenas presentan variaciones significativas en la parte sureste del

Tabla 1. Coeficientes de correlación de Pearson para temperaturas superficiales

\begin{tabular}{|c|c|c|c|}
\hline Variables & $\begin{array}{l}\text { Coeficiente } \\
\text { de Pearson }\end{array}$ & Variables & $\begin{array}{l}\text { Coeficiente } \\
\text { de Pearson }\end{array}$ \\
\hline $\begin{array}{l}\text { Temperatura calculada en función de la altura } \\
\text { versus temperatura calcula por SR para el día } \\
15 / 9 / 2015\end{array}$ & 0,2104 & $\begin{array}{l}\text { Temperatura medida en superficie versus } \\
\text { temperatura calcula por SR para el día } \\
15 / 9 / 2015\end{array}$ & 0,2746 \\
\hline $\begin{array}{l}\text { Temperatura calculada en función de la altura } \\
\text { versus temperatura calcula por SR para el día } \\
\text { 20/11/2016 }\end{array}$ & 0,1928 & $\begin{array}{l}\text { Temperatura medida en superficie versus } \\
\text { temperatura calcula por SR para el día } \\
20 / 11 / 2016\end{array}$ & 0,0547 \\
\hline $\begin{array}{l}\text { Temperatura calculada en función de la altura } \\
\text { versus temperatura calcula por SR para el día } \\
\text { 23/1/2017 }\end{array}$ & 0,4388 & $\begin{array}{l}\text { Temperatura medida en superficie versus } \\
\text { temperatura calcula por SR para el día } \\
\text { 23/1/2017 }\end{array}$ & 0,3627 \\
\hline
\end{tabular}

Fuente: Elaboración propia. 
Tabla 2. Coeficientes de correlación de Pearson para temperaturas en profundidad

\begin{tabular}{|c|c|c|c|}
\hline Variables & $\begin{array}{l}\text { Coeficiente } \\
\text { de Pearson }\end{array}$ & Variables & $\begin{array}{l}\text { Coeficiente } \\
\text { de Pearson }\end{array}$ \\
\hline $\begin{array}{l}\text { Temperatura a } 20 \mathrm{~cm} \text { normalizada versus } \\
\text { temperatura calcula por SR para el día 15/9/2015 } \\
\text { normalizada a } 20 \mathrm{~cm}\end{array}$ & 0,1104 & $\begin{array}{l}\text { Temperatura a } 20 \mathrm{~cm} \text { versus temperatura } \\
\text { calcula por SR para el día 15/9/2015 }\end{array}$ & 0,2153 \\
\hline $\begin{array}{l}\text { Temperatura a } 20 \mathrm{~cm} \text { normalizada versus } \\
\text { temperatura calcula por SR para el día 20/11/2016 } \\
\text { normalizada a } 20 \mathrm{~cm}\end{array}$ & $-0,3012$ & $\begin{array}{l}\text { Temperatura a } 20 \mathrm{~cm} \text { versus temperatura } \\
\text { calcula por SR para el día 20/11/2016 }\end{array}$ & 0,1588 \\
\hline $\begin{array}{l}\text { Temperatura a } 20 \mathrm{~cm} \text { normalizada versus } \\
\text { temperatura calcula por SR para el día 23/1/2017 } \\
\text { normalizada a } 20 \mathrm{~cm}\end{array}$ & $-0,5055$ & $\begin{array}{l}\text { Temperatura a } 20 \mathrm{~cm} \text { versus temperatura } \\
\text { calcula por SR para el día 23/1/2017 }\end{array}$ & 0,4051 \\
\hline $\begin{array}{l}\text { Temperatura a } 100 \mathrm{~cm} \text { normalizada versus } \\
\text { temperatura calcula por SR para el día 15/9/2015 } \\
\text { normalizada a } 100 \mathrm{~cm}\end{array}$ & 0,0863 & $\begin{array}{l}\text { Temperatura a } 100 \mathrm{~cm} \text { versus temperatura } \\
\text { calcula por SR para el día } 15 / 9 / 2015\end{array}$ & 0,1971 \\
\hline $\begin{array}{l}\text { Temperatura a } 100 \mathrm{~cm} \text { normalizada versus } \\
\text { temperatura calcula por SR para el día 20/11/2016 } \\
\text { normalizada a } 100 \mathrm{~cm}\end{array}$ & $-0,1871$ & $\begin{array}{l}\text { Temperatura a } 100 \mathrm{~cm} \text { versus temperatura } \\
\text { calcula por SR para el día 20/11/2016 }\end{array}$ & 0,1947 \\
\hline $\begin{array}{l}\text { Temperatura a } 100 \mathrm{~cm} \text { normalizada versus } \\
\text { temperatura calcula por SR para el día 23/1/2017 } \\
\text { normalizada a } 100 \mathrm{~cm}\end{array}$ & $-0,211$ & $\begin{array}{l}\text { Temperatura a } 100 \mathrm{~cm} \text { versus temperatura } \\
\text { calcula por SR para el día 23/1/2017 }\end{array}$ & 0,4480 \\
\hline $\begin{array}{l}\text { Temperatura a } 150 \mathrm{~cm} \text { normalizada versus } \\
\text { temperatura calcula por SR para el día 15/9/2015 } \\
\text { normalizada a } 150 \mathrm{~cm}\end{array}$ & 0,2994 & $\begin{array}{l}\text { Temperatura a } 150 \mathrm{~cm} \text { versus temperatura } \\
\text { calcula por SR para el día 15/9/2015 }\end{array}$ & 0,1954 \\
\hline $\begin{array}{l}\text { Temperatura a } 150 \mathrm{~cm} \text { normalizada versus } \\
\text { temperatura calcula por SR para el día 20/11/2016 } \\
\text { normalizada a } 150 \mathrm{~cm}\end{array}$ & 0,3727 & $\begin{array}{l}\text { Temperatura a } 150 \mathrm{~cm} \text { versus temperatura } \\
\text { calcula por SR para el día 20/11/2016 }\end{array}$ & 0,2084 \\
\hline $\begin{array}{l}\text { Temperatura a } 150 \mathrm{~cm} \text { normalizada versus } \\
\text { temperatura calcula por SR para el día 23/1/2017 } \\
\text { normalizada a } 150 \mathrm{~cm}\end{array}$ & $-0,7810$ & $\begin{array}{l}\text { Temperatura a } 150 \mathrm{~cm} \text { versus temperatura } \\
\text { calcula por SR para el día 23/1/2017 }\end{array}$ & 0,4677 \\
\hline
\end{tabular}

Fuente: Elaboración propia.

área de trabajo por donde se evidencia el trazo de la falla Guachucal. El NDVI para el día 15/9/2015 muestra que gran parte de la vegetación tiene tonalidades rojas con valores aproximados a 0,890 y con un valor mínimo de $-0,131$ al sureste de la cabecera municipal de El Espino (figura 3a). Los índices de vegetación calculados para el día 20/11/2016 varían entre 0,892 y $-0,151$, lo que evidencia que la mayoría de la vegetación del área de estudio se encuentra libre de algún tipo de estrés. La zona que presenta tonalidades verdes, con los valores más bajos, corresponde a la zona más sureste, coincidente con el trazo de la falla Guachucal (figura 3b). Por último, el NDVI para el día 23/1/2017 (figura 3c) denota los índices más altos (cercanos a 0,936), pero también los índices más bajos de los tres periodos evaluados $(-0,563)$. Espacialmente, los valores más bajos coinciden con los niveles digitales encontrados para la laguna Verde, cuerpo de agua que se encuentra próximo al cráter del volcán Azufral. Los valores medios son positivos, cercanos a 0,018 , lo que tiene consistencia con los tonos mayoritariamente rojos en el área de trabajo.

\section{Secciones cruzadas de temperatura, NVDI y topografía}

Para comparar espacialmente la distribución de las temperaturas en función de la profundidad en el área de estudio y de las imágenes Landsat 8 TIRS, 
que incluye además los NDVI y la topografía, se trazaron dos secciones cruzadas (figura 4), una en sentido oeste-este (A-A') y otra en sentido suroeste-noreste (B-B'). Las convenciones para cada una de las variables que se deben correlacionar en las secciones cruzadas se muestran en la tabla 3.
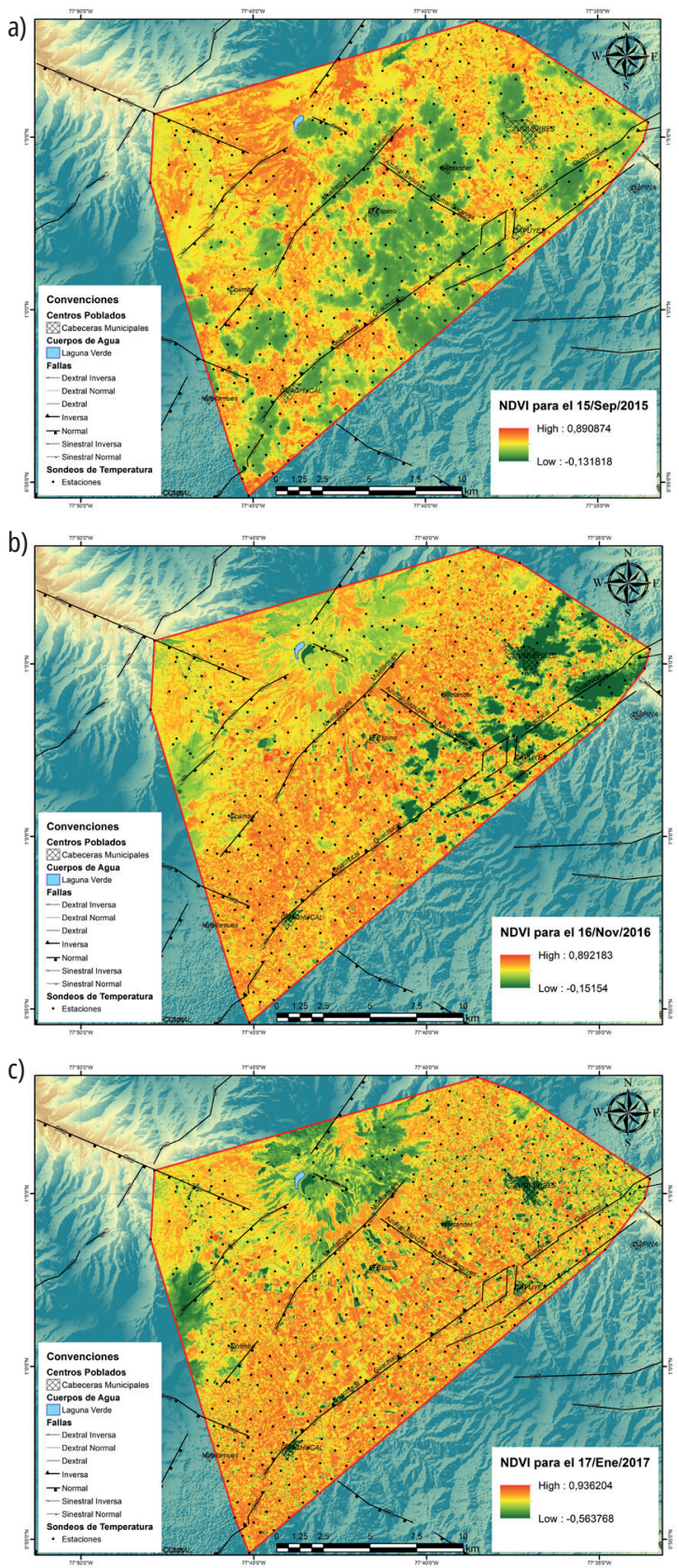

Figura 3. NDVI en mapas y perfiles para las imágenes Landsat 8 TIRS. Fuente: Elaboración propia.
En cada sección cruzada, se correlacionaron las temperaturas calculadas y medidas en superficie, y en profundidad, las temperaturas estimadas a partir de Landsat 8 TIRS y los NDVI calculados para cada uno de los días analizados.

\section{Sección cruzada A-A'}

Al contrastar las temperaturas calculadas y medidas superficialmente, se observa en la figura $5 \mathrm{a}$ que las temperaturas a $20 \mathrm{~cm}, 100 \mathrm{~cm}$ y $150 \mathrm{~cm}$ alcanzan un valor mínimo de $9,4^{\circ} \mathrm{C}$ (sector central del área-sur del volcán Azufral, cercano a la falla Muellamues) y máximo de $16,5^{\circ} \mathrm{C}$ (parte occidental del volcán Azufral). Las tres profundidades presentan el mismo comportamiento a lo largo de la sección cruzada (figura 5a), que marca la anomalía positiva más alta al inicio de la sección y la anomalía negativa más baja en inmediaciones del sector sur del volcán Azufral (influencia de la falla Muellamues). En cuanto a las temperaturas encontradas a partir de Landsat 8 TIRS, se evidencia un contraste entre la imagen del día 15/9/2015 y las imágenes de los días 20/11/2016 y 23/1/2017 (figura 5b). La gran diferencia de temperaturas puede deberse a nivel de radiancia capturado en los niveles digitales de la imagen como en las condiciones climáticas y de enmascaramiento por nubosidad en el área de trabajo (que afecta el nivel digital y por ende el valor obtenido de la radiancia para el cálculo posterior de la temperatura). La sección cruzada denota que las temperaturas de la imagen del día 15/9/2015 contiene los rangos más altos (hasta $\left.32^{\circ} \mathrm{C}\right)$ y más bajos $\left(2^{\circ} \mathrm{C}\right)$ de temperatura. A su vez, se observa una anomalía negativa para la imagen del día 20/11/2016, que alcanza los $5^{\circ} \mathrm{C}$ y contrasta con las temperaturas del día 23/1/2017, que en ese mismo sector (cabecera municipal de Túquerres) presentan temperaturas constantes a $22^{\circ} \mathrm{C}$. Los NDVI (figura $5 \mathrm{c}$ ) muestran una tendencia de índices más bajos para los valores del día 15/9/2015. Para los días 20/11/2016 y 23/1/2017, los NDVI conservan una tendencia similar en la mayor parte de la sección, que incluye el valor más bajo para los índices en la cabecera municipal de Túquerres $(0,10-0,15)$. 


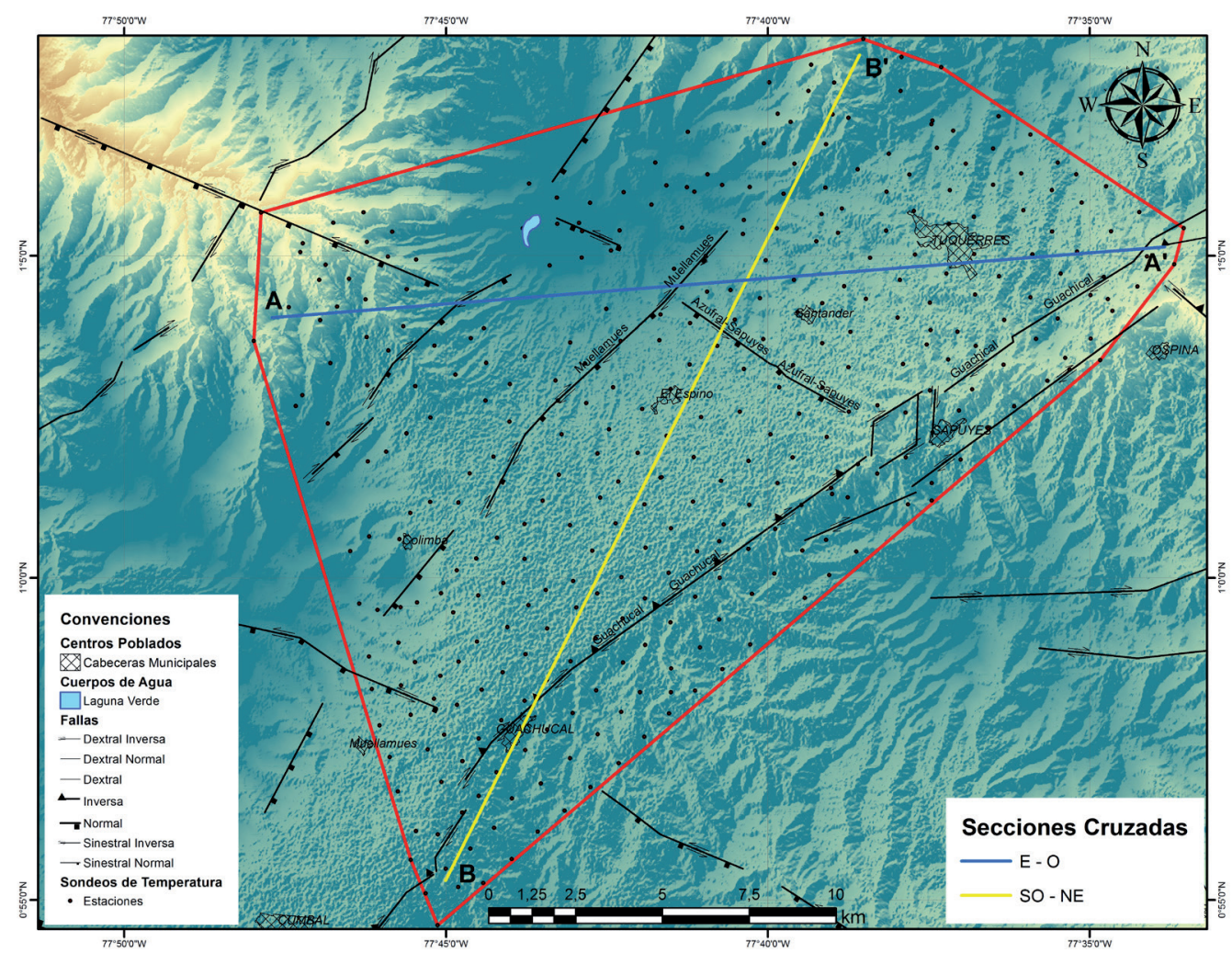

Figura 4. Localización de las secciones cruzadas en el área de trabajo con el MDE y el esquema estructural, que fue tomado de [20]. Fuente: Elaboracion propia.

Tabla 3. Convenciones para los análisis por variable en las secciones cruzadas

\begin{tabular}{|c|c|c|c|c|}
\hline $\begin{array}{l}\text { Temperatura } \\
\text { calculada a } 0 \mathrm{~cm}\end{array}$ & $\begin{array}{l}\overline{\text { Temperatura }} \\
\text { medida a } 0 \mathrm{~cm}\end{array}$ & $\begin{array}{l}\text { Temperatura } \\
\text { medida a } 20 \mathrm{~cm}\end{array}$ & $\begin{array}{l}\text { Temperatura } \\
\text { medida a } 100 \mathrm{~cm}\end{array}$ & $\begin{array}{l}\text { Temperatura } \\
\text { medida a } 150 \mathrm{~cm}\end{array}$ \\
\hline & $\begin{array}{c}\overline{\text { Temperatura }} \\
\text { calculada para 15/9/2015 }\end{array}$ & $\begin{array}{c}\text { Temperatura } \\
\text { calculada para 20/11/2016 }\end{array}$ & $\begin{array}{c}\text { Temperatura } \\
\text { calculada para 23/1/2017 }\end{array}$ & \\
\hline & $\begin{array}{c}\text { NDVI } \\
\text { para 15/9/2015 }\end{array}$ & $\begin{array}{c}\text { NDVI } \\
\text { para 20/11/2016 }\end{array}$ & $\begin{array}{c}\text { NDVI } \\
\text { para 23/1/2017 }\end{array}$ & \\
\hline
\end{tabular}

Fuente: Elaboración propia.

La topografía presente en la longitud de la sección cruzada (figura 5d) permite observar el costado sureste del edificio volcánico como un alto topográfico entre los 3300 msnm y 3600 msnm y la evidencia de las fallas Cali-Patía, Muellamues y Guachucal. Las alturas más bajas se encuentran en los extremos de la sección cruzada, que alcanzan alturas entre los $2780 \mathrm{msnm}$ (extremo oeste) y los $2800 \mathrm{msnm}$ (extremo este).

\section{Sección cruzada $B-B^{\prime}$}

En la sección cruzada B-B', sentido suroeste-noreste (figura 4), las temperaturas a 20,100 y $150 \mathrm{~cm}$ se mantienen en un rango de $11,8^{\circ} \mathrm{C}$ y los $16,1^{\circ} \mathrm{C}$. La anomalía positiva se observa en uno de los extremos de la sección (parte más noreste del área de trabajo) y la anomalía más negativa cercana al cruce de las fallas Muellamues y Azufral-Sapuyes. 

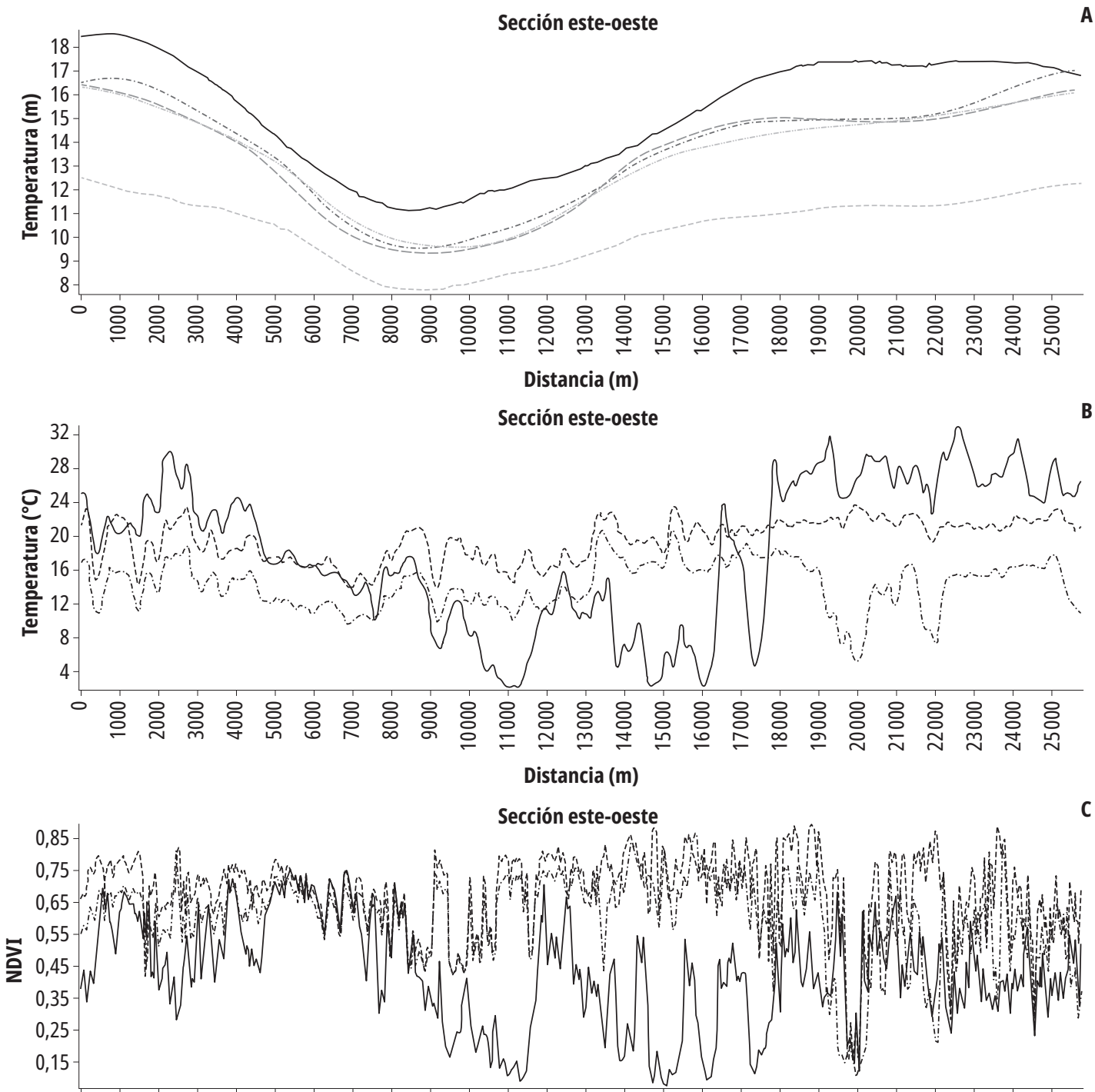

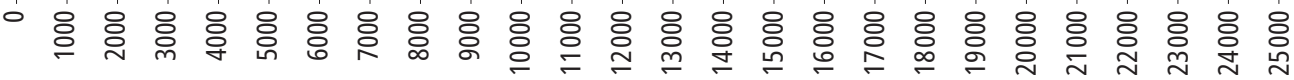

Distancia ( $m$ )

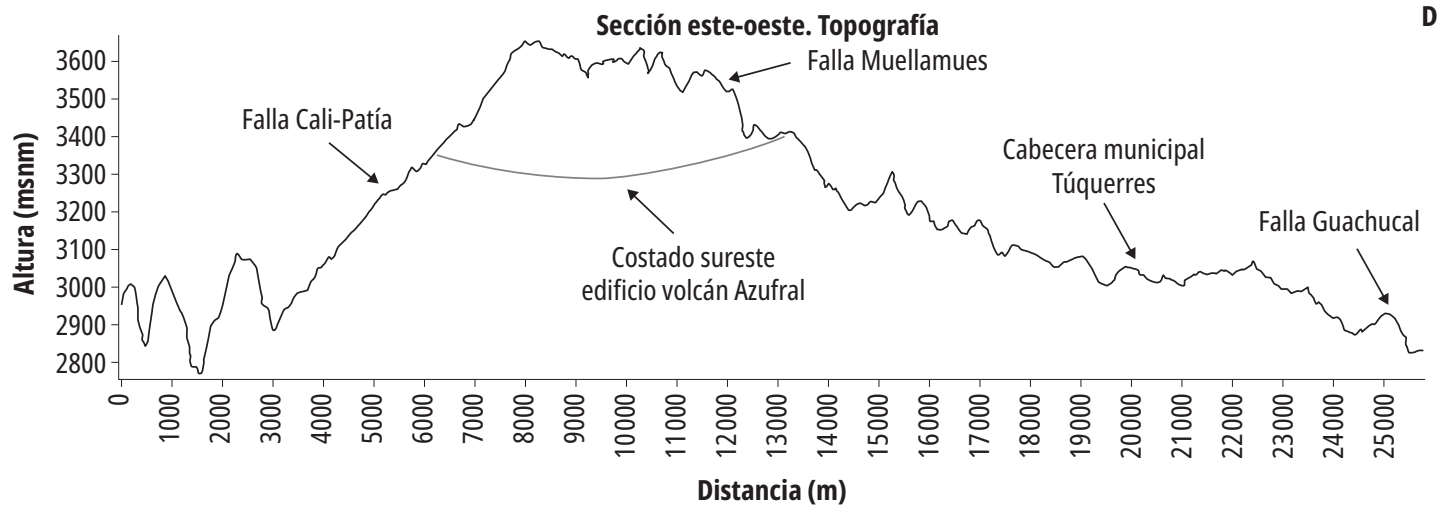

Figura 5. Correlación de SST (a), temperaturas de Landsat 8 TIRS (b), NDVI (c) y topografía (d) en la sección cruzada A-A'. Fuente: Elaboración propia. 
Se percibe que la temperatura medida en superficie es más cercana en esta sección B-B' (figura 6a) a las temperaturas estimadas en profundidad, contrario a la temperatura calculada mediante la ecuación (1), que se comporta en rango aproximado de los $11^{\circ} \mathrm{C}$ con una baja hacia el sector noreste de $9^{\circ} \mathrm{C}$. Las temperaturas estimadas a partir de Landsat 8 TIRS en la sección cruzada presentan en la imagen del día 15/9/2015 las temperaturas más bajas con patrones de contrastes extremos muy marcados (figura 6b), que alcanza variaciones entre los $2^{\circ} \mathrm{C}$ y los $30^{\circ} \mathrm{C}$. Las temperaturas para las imágenes de los días 20/11/2016 y 23/1/2017 conservan un patrón similar para las anomalías de temperatura medidas en campo. Los rangos de temperatura que se logran el día 20/11/2016 se mantiene entre los $13^{\circ} \mathrm{C}$ y los $21^{\circ} \mathrm{C}$. Para el día 23/1/2017, las variaciones de temperatura se concentran entre los $15^{\circ} \mathrm{C}$ y los $25^{\circ} \mathrm{C}$. En la sección cruzada, se presenta una anomalía positiva en el sector sur del volcán Azufral con $21^{\circ} \mathrm{C}$ y $25^{\circ} \mathrm{C}$, para los días 20/11/2016 y 23/1/2017, respectivamente. Los NDVI que se evidencian (figura 6c) para el día 15/9/2015 alcanzan los valores más bajos (hasta 0,1 ) en la central de la sección cruzada. Para los días 20/11/2016 y $23 / 1 / 2017$, se denota NDVI bajos asociados a la localización de las cabeceras municipales de Guachucal y de El Espino, donde la vegetación existente tiende a ser nula por la urbanización de los cascos urbanos. En las partes más bajas del altiplano nariñense [19] presentes en el área de trabajo, se enmarcan dos cabeceras municipales (Guachucal y El Espino) y tres fallas que cortan transversalmente (fallas Guachucal, Azufral-Sapuyes y Muellamues) la sección cruzada B-B'. El alto topográfico más notorio varía desde los $3200 \mathrm{msnm}$ hasta los 3400 msnm, que delimita tangencialmente (por su cercanía) el costado más oriental del edificio del volcán Azufral. Las alturas más bajas se encuentran en el extremo noreste de la sección cruzada, que alcanza alturas de $2950 \mathrm{msnm}$.

\section{Conclusiones}

La consolidación de los sensores remotos como herramienta para la generación de modelos de temperatura superficial se robustece como una opción real para la exploración de recursos geotérmicos en las áreas de interés del territorio colombiano.

Los SST como verdad terreno constituyen una primera perspectiva de la distribución de calor en el área geotérmica del volcán Azufral. A su vez, los sensores remotos aportan la validación de la estructura geotérmica del área, por medio de la integración de los NDVI y de las temperaturas estimadas para los diversos días de estudio. La influencia de la topografía es un criterio importante debido a la influencia de esta variable tanto para la consecución de las mediciones de campo como para la injerencia de la altitud en los factores de corrección a los niveles digitales de la imagen de satélite.

Los mapas de anomalías de temperatura generados a partir de las mediciones de los SST muestran una anomalía negativa, con temperaturas entre los $6^{\circ} \mathrm{C}$ y $9^{\circ} \mathrm{C}$, tanto en superficie como en todas las profundidades caracterizadas $(20 \mathrm{~cm}$, $100 \mathrm{~cm}, 150 \mathrm{~cm}$ ) en el sector, localizada en el edificio del volcán Azufral, con tendencia hacia la parte oriental. En las mediciones de $150 \mathrm{~cm}$, se observa una anomalía positiva (entre los $16^{\circ} \mathrm{C}$ y $18^{\circ} \mathrm{C}$ ) de temperatura ubicada en el sector de la cuenca de tracción formada por la falla Guachucal, que conforma un corredor de altas temperaturas por el trazo nororiental de la misma falla.

Al evaluar las correlaciones de Pearson, se observa que las correlaciones negativas están vinculadas a las normalizaciones aplicadas a las temperaturas calculadas con sensores remotos. Esto se debe a que las variaciones de la radiancia en los niveles digitales de la imagen son mucho más altos que los valores de la escala de los mapas arrojados en profundidad.

La utilización de los NDVI calculados para cada una de las imágenes en los periodos de tiempo establecidos corroboró que varias anomalías positivas de temperatura se encuentran asociadas a suelos con otras coberturas vegetales o de vegetación en el área de trabajo (sección suroeste-noreste).

Las correlaciones negativas encontradas por mediodelcoeficientedePearson indicanlaincidencia directa de la resolución temporal de las imágenes en los modelos de temperatura. La eliminación 

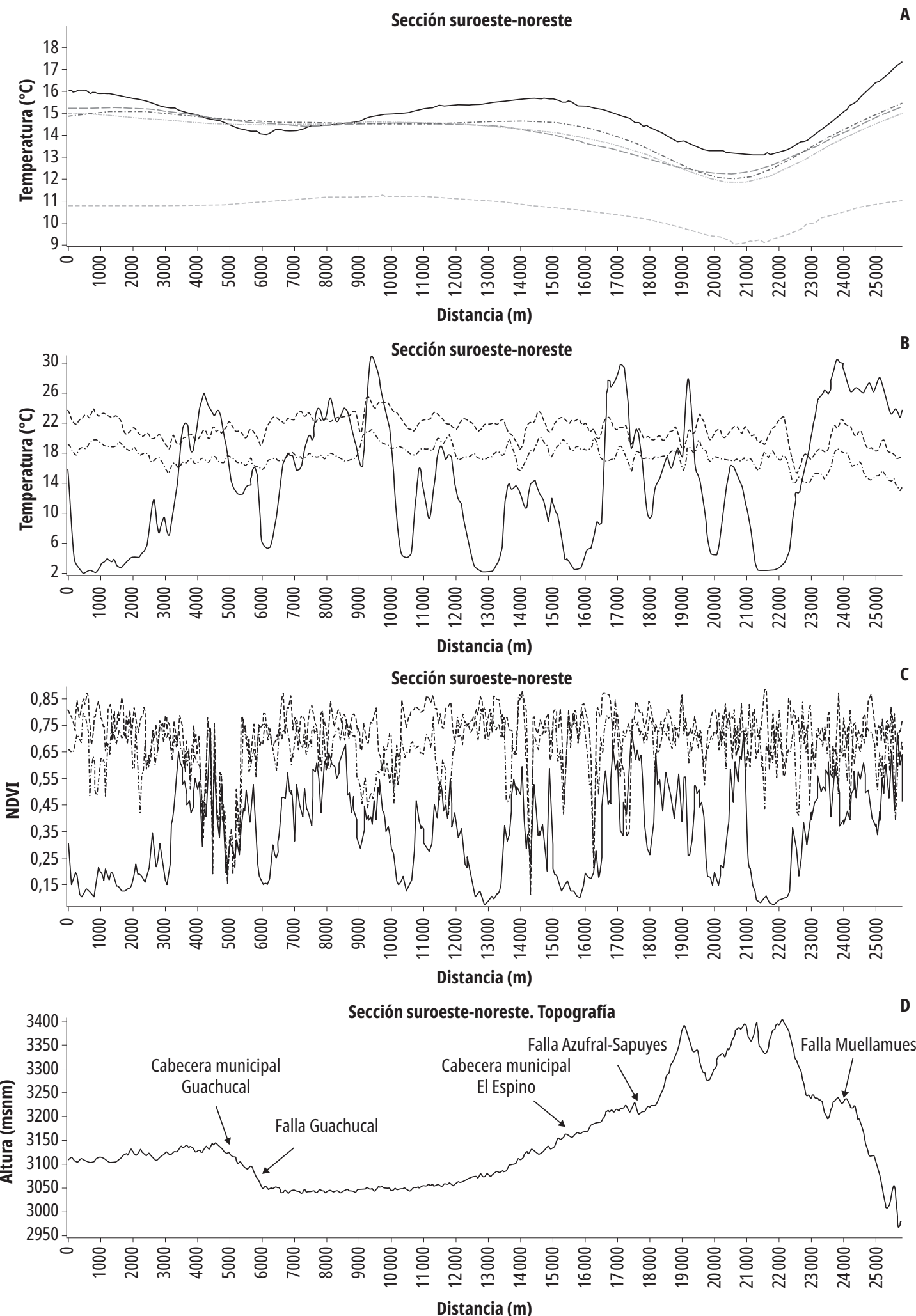

Figura 6. Correlación de SST (a), temperaturas de Landsat 8 TIRS (b), NDVI (c) y topografía (d) en la sección cruzada B-B'. Fuente: Elaboración propia. 
de las fluctuaciones temporales hacia un solo momento referente de tiempo, mediante la estimación de una regresión lineal en una serie de imágenes que cubran el área de trabajo, permitiría aumentar la correlación positiva entre los modelos generados por sensores remotos frente a la verdad terreno (SST).

El área de estudio presenta variaciones en la topografía, que ratifican las mediciones en terreno de las temperaturas, a la espera de que los valores asociados al sector del volcán Azufral sean anomalías positivas de temperatura. Estos altos de temperatura se asocian con las coberturas de suelo encontradas en la parte alta del volcán, ya que en los NDVI se relacionan con índices negativos, lo que indica la presencia de suelos semidesnudos con vegetación de páramo.

La identificación de las anomalías de temperatura encontradas en un área geotérmica como la del volcán Azufral tiene el potencial de reducir costos y de constreñir los componentes de un área geotérmica en la etapa temprana de exploración. A su vez, para los usos directos, específicamente en la instalación de intercambiadores de calor para uso doméstico, son de gran utilidad, ya que, al mapear las anomalías cercanas a la superficie, se establece una relación directa con las profundidades donde se puede explotar el recurso de esta manera.

El procesamiento de imágenes con datos en las bandas del infrarrojo térmico permite dar una primera pauta en la identificación de posibles anomalías de temperatura cercanas a la superficie que no necesariamente dependen de un sistema de flujo de calor convectivo, y así lograr interpretar con una primera herramienta las variaciones de la temperatura para sistemas geotérmicos conductivos (como los presentes en cuencas sedimentarias).

\section{Agradecimientos}

Los autores agradecen a la Dirección Técnica de Geociencias Básicas del Servicio Geológico Colombiano (SGC), por brindar el apoyo y la financiación al proyecto de "Exploración de recursos geotérmicos en el área geotérmica del volcán Azufral (Nariño)", del cual se derivó el análisis de la distribución de calor en el área geotérmica del volcán Azufral a partir de sondeos superficiales de temperatura, estudio que fue parte esencial y primordial como insumo en esta investigación.

\section{Referencias}

[1] M. Coolbaugh, C. Sladek, R. Zehner y C. Kratt, "Shallow Temperature Surveys for Geothermal Exploration in the Great Basin, USA, and Estimation of Shallow Aquifer Heat Loss", GRC Transactions, vol. 38, pp. 115122, 2014.

[2] M. F. Coolbaugh, C. Sladek, J. E. Faulds, R. E. Zehner y G. L. Oppliger, "Use of rapid temperature measurements at a 2-meter depth to augment deeper temperature gradient drilling", en Proceedings. Thirty-Second Workshop on Geothermal Reservoir Engineering, Stanford University, Stanford, 2007.

[3] F. H. Olmsted y S. E. Ingebritsen, "Shallow subsurface temperature surveys in the basin and range province-II. Ground temperatures in the Upsal Hogback geothermal area, West-Central Nevada, USA", Geothermics, vol 15, no. 3, pp. 267-275, 1986.

[4] C. Kratt, M. Coolbaugh, B. Peppin y C. Sladek, "Identification of a new blind geothermal system with hyperspectral remote sensing and shallow temperature measurements at Columbus Salt Marsh, Esmeralda County, Nevada", Geothermal Resources Council Transactions, vol. 33, pp. 481-485, 2009.

[5] G. R. Beardsmore, "Towards a shallow heat flow probe for mapping thermal anomalies", en Proceedings. Thirty-Seventh Workshop on Geothermal Reservoir Engineering, Stanford University, Stanford, 2012, pp. 1-14.

[6] G. M. Mwawongo, "Geothermal mapping temperature measurements", en Short Course II on Surface Exploration for Geothermal Resources, Lake Naivasha, Kenia, 2013.

[7] M. Abouriche, Temperature measurements at the surface and in shallow drillholes. Reykjavík: ONU Geothermal Training Programme, 1989.

[8] M. H. Badii, A. Guillen, O. P. Lugo Serrato y J. J. Aguilar Garnica, "Correlación no-paramétrica y su aplicación en la investigaciones científicas", International Journal of Good Conscience, vol. 2, no. 9, pp. 31-40, ag., 2014.

[9] L. C. Becerra González, J. C. Matiz León, O. Ariza Ariza, D. C, Borda Beltrán y J. Medina, “Aplicación de imágenes de satélite y de sistemas UAV para la producción de guayaba en la provincia de Vélez, Santander”, UD y la Geomática, no. 11, pp. 46-53, 2017.

[10] G. Norini, G. Groppelli, R. Sulpizio, G. Carrasco-Núñez, P. Dávila-Harris, C. Pellicioli, F. Zucca y R. de Franco, "Structural analysis and thermal remote sensing of the Los Humeros Volcanic Complex: 
implications for volcano structure and geothermal exploration", Journal of Volcanology and Geothermal Research, vol. 301, pp. 221-237, ag., 2015.

[11] G. Rodríguez, Análisis de la distribución de calor en el área geotérmica del volcán Azufral a partir de sondeos superficiales de temperatura. Bogotá: Servicio Geológico Colombiano, 2016.

[12] U.S. Geological Survey, Landsat (L8), Data Users Handbook. Sioux Falls. South Dakota: Geological Survey, 2016.

[13] T. G. Farr, P. A. Rosen, E. Caro, R. Crippen, R. Duren, S. Hensley, M. Kobrick, M. Paller, E. Rodriguez, L. Roth, D. Seal, S. Shaffer, J. Shimada, J. Umland, M. Werner, M. Oskin, D. Burbank y D. Alsdorf, “The shuttle radar topography mission", Reviews of Geophysics, vol. 45, no. 2, pp. 1-33, my., 2007. https://doi.org/10.1029/2005RG000183

[14] J. Eslava, "Perfil altitudinal de la temperatura media del aire en Colombia", Geofísica Colombiana, no. 1, pp. 37-52, oct., 1992.

[15] M. Li, S. H. Liu, H. Z. Zhou, X. Li y P. J. Wang, “The temperature research of urban residential area with remote sensing", en Proceedings. 2005 IEEE International Geoscience and Remote Sensing Symposium, Seúl, Corea del Sur, 2005, pp. 1514-1517.

[16] A. Mermer, H. Yildiz, E. Ünal, M. Aydoğdu, A. Özaydın, F. Dedeoğlu, O. Urla, O. Aydoğmuş, H.
Torunlar, M. Tuğaç, A. Avağ, S. Ünal y Z. Mutlu, "Monitoring rangeland vegetation through time series satellite images (NDVI) in Central Anatolia Region", en 2015 Fourth International Conference on Agro-Geoinformatics (Agro-geoinformatics), Estambul, Turquía, pp. 213-216, 2015. DOI: 10.1109/Agro-Geoinformatics.2015.7248137

[17] L. F. Restrepo y J. González, "From pearson to Spearman”, Revista Colombiana de Ciencias Pecuarias, vol. 20, no. 2, pp. 183-192, abr.-jun., 2007.

[18] E. Borgogno-Mondino y A. Lessio, "Estimation and mapping of NDVI uncertainty from Landsat 8 OLI datasets: an operational approach", en 2015 IEEE International Geoscience and Remote Sensing Symposium (IGARSS), Milán, Italia, pp. 629-632, 2015. DOI: 10.1109/IGARSS.2015.7325842

[19] G. Rodríguez Ospina y J. Rueda Gutiérrez, Geología estructural del área geotérmica del volcán Azufral. Bogotá: Servicio Geológico Colombiano, 2017.

[20] A. Pinilla, P. Ríos y B. Rodríguez, Memoria explicativa Azufral 25k. Bogotá: Universidad Nacional de Colombia, 2007. 
